\title{
Diversion colitis 25 years later: the phenomenon of the disease
}

\author{
Marek Szczepkowski $^{1,2}$ - Tomasz Banasiewicz ${ }^{3} \cdot$ Adam Kobus $^{1}$
}

Accepted: 23 March 2017 / Published online: 29 March 2017

(C) The Author(s) 2017. This article is published with open access at Springerlink.com

\begin{abstract}
Background Diversion colitis (DC) seems to be common in stoma patients, and the restoration of the continuity of the digestive tract is crucial for relief from the inflammatory process. No prospective studies of the late effects of DC on the lower gastrointestinal (GI) tract mucosa and the clinical condition of patients have been reported.

Methods Data from 23 patients who underwent stoma creation were analysed during the reversal period $(\mathrm{A})$ and at an average of 3 months (B1) and 5.6 years (B2) after restoration of GI tract continuity. Every monitoring visit included endoscopy, histology and assessment of the clinical condition of patients.

Results Shortly after GI tract restoration (B1), a significant decrease in inflammation was observed. The Ki67 positivity percentage increased, but this was not significant. At an average of 5.6 years after restoration (group B2), the clinical symptoms were mild. More patients presented with endoscopically detected inflammation of the mucosa, but its severity was not significantly higher than that at 3 months after reversal. Histological inflammation was more common, and its severity was significantly higher than that shortly after reversal but similar to that before reversal. The Ki67 positivity percentage decreased at the last examination (B2).
\end{abstract}

Tomasz Banasiewicz

tbanasiewicz@op.pl

1 Clinical Department of General and Colorectal Surgery, Bielanski Hospital, Warsaw, Poland

2 Department of Rehabilitation, Józef Piłsudski University of Physical Education, Warsaw, Poland

3 Department of General, Endocrynological Surgery and Gastrointestinal Oncology, Poznan University of Medical Sciences, ul. Przybyszewskiego 49, 60-355 Poznań, Poland
Conclusions The results of this study show a complex recurrence of histological inflammation several years after GI tract restoration but without clinical and endoscopic inflammation and with good clinical condition. DC can potentially have a late influence on the rectal mucosa, even after stoma closure.

Keywords Diversion colitis $\cdot$ Rectal stump $\cdot$ Inflammation · Mucosal proliferation

\section{Introduction}

Diversion colitis was described by Glotzer et al. in 1981 [1]. Twenty-five years ago, Harig et al. published the first report of its treatment using short-chain fatty acids (SCFA) [2]. Despite the inclusion of only four patients, the study has become a classic regarding the treatment of this condition. Diversion colitis (DC) is characterized by bleeding from an inflamed large bowel mucosa that mimics idiopathic inflammatory bowel disease and that may lead to stricture formation. For many years, there were no criteria for the assessment of the severity of DC, and very little was known about the long-term effects of DC on the condition of the gastrointestinal (GI) mucosa. Some papers report the occurrence of inflammation and development of new clinical symptoms months after stoma reversal $[3,4]$. To date, there are 295 publications in PubMed that include the key words 'diversion colitis', but in most of these reports, DC is reported incidentally during analysis of other clinical conditions.

We therefore carried out a study to examine the long-term consequences in the rectal mucosa of diversion colitis resulting from proximal stoma formation for various pathologies in a group of patients followed over 5 or more years after closure of the stoma. 
Table 1 Clinical characteristics of the study group

Clinical characteristics

Age

Sex

Primary diagnosis (reason for stoma creation)
61.6 years (min. 47 ; max. 81$)$

F 11

M 12

Colorectal cancer 9

Diverticulitis 11

Bowel traumatic injury 2

Iatrogenic perforation 1

372 (min. 132; $\max .982$ )

88 (min. 78; $\max .102$ )

2038 (min. 1472; max. 2889)

19.5 (min. 8; max. 60)

\section{Method}

The prospective study included patients who had undergone partial colonic resection with the simultaneous creation of a temporary colostomy (Table 1).

In all cases, sigmoidostomy was created. Initially, there were 52 eligible patients. The indications for primary surgery included colorectal cancer (20 patients), diverticulitis (23 patients), volvulus of the sigmoid colon (1 patient), ovarian cancer ( 3 patients), traumatic bowel injury (5 patients) and iatrogenic perforation ( 2 patients). The initial exclusion criteria were the presence of inflammatory bowel disease such as Crohn's disease or ulcerative colitis and anastomotic leakage after rectal cancer surgery.

The 52 patients were operated on at the Bielanski Hospital between 2003 and 2008, and the continuity of their digestive tract was restored. The patients were included in a follow-up programme involving regular monitoring examinations by endoscopy, histology and clinical assessment. The long followup resulted in drop-out of some of the patients because of death due to other reasons, loss of contact with patient or lack of acceptation the control investigation by the well-doing patients. The final analysed group consisted of 23 patients operated on for colorectal cancer (9 patients), diverticulitis (11 patients), bowel traumatic injury (2 patients) and iatrogenic perforation (1 patient) (Fig. 1). The interval from the formation of the stoma to its closure was a median of 50.3 weeks.

\section{Clinical investigation}

Each patient was investigated on three occasions as follows: 2 weeks before colostomy closure (period A), 3 months (period $\mathrm{B} 1$ ) after colostomy, and between 4 and 8 years (median 5.6 years) (period B2) after stoma closure. At every investigation, patients completed a questionnaire and underwent rigid rectosigmoidoscopy and mucosal biopsy using flexible colonoscopy. The basic demographic data of the patients were also recorded. The questionnaire included questions about clinical symptoms including mucous discharge, cramping abdominal pain and tenesmus. Every symptom was scored as 0 -absent, 1 -mild or 2-severe. To compare the results of the scoring, a control group was also created (group C). This consisted of 15 patients undergoing endoscopy before haemorrhoidectomy. No pathology other than haemorrhoids was found in these patients by colonoscopy.

\section{Endoscopic examination}

One endoscopist performed the endoscopies for all patients. Mechanical bowel preparation before endoscopy was omitted to reduce bias. Random biopsies (three specimens) were performed on the rectum approximately $7 \mathrm{~cm}$ above the dentate line, even in patients with normal endoscopic findings. The endoscopist was blinded to the patient's symptoms. The endoscopic findings were expressed according to the scoring system of Harig et al. [1] including erythema, oedema, friability, granularity and erosions. Every finding was scored as grade 0 - absent, grade 1 - mild or grade 2 - severe.

\section{Histopathological examination}

The histopathological severity of colitis was assessed by two independent histopathologists blinded to the patient's clinical data. The average score of the two investigations was used in further analysis. The histopathological findings were scored as acute inflammation (0 to 1), chronic inflammation (0 to 2), eosinophilic infiltration (0 to 2), crypt architecture distortion ( 0 to 1 ), follicular lymphoid hyperplasia ( 0 to 1 ) and crypt abscess (0 to 1$)$. The total score was validated and further defined as mild (1 to 3 ), moderate (4 to 6 ) or severe (7 to 8 ) [3]. 


\section{Immunohistological examination for Ki67}

The monoclonal antibody Ki67 (DakoCytomation, M7240) was used to assess the cell turnover of the mucosa. In all specimens, chromogen 3,3'-diaminobenzidine (DakoCytomation, K5007) was used for antigen localization. Stained sections were analysed field-by-field at a final magnification of $400 \times$. Each field was assigned a continuous score of positivity percentage, representative of the approximate area of immunostaining. The staining reaction obtained after the exclusion of the primary antibody was used as a negative control.

\section{Statistical analysis}

Statistical analysis was performed using $\mathrm{R}$ statistical package [5]. Spearman's rank correlation was used for ordinal data correlation analysis. Analysis of values between independent groups that did not meet the criteria for normal distribution defined by the Shapiro-Wilk test was performed using the Wilcoxon matched-pairs test for paired and the MannWhitney test for unpaired variables. The same tests were used when comparing ordinal values in two independent groups. When comparing two dependent groups, we used the Wilcoxon signed-rank test. Comparison of ordinal values in more than two dependent groups was performed using Friedman's test with a Wilcoxon-Mann-Whitney test as a post hoc test. Wherever more than one analysis of the same data was performed, we used the Bonferroni correction for the $p$ value.

Ethical considerations The study was performed with the consent of the Ethics Committee of Centre for Postgraduate Medical Education, Warsaw, Poland.
Fig. 1 A flowchart representing the course of the study of DC patients
Patients after stoma creation in Bielanski Hospital; $\mathbf{n}=\mathbf{5 2}$

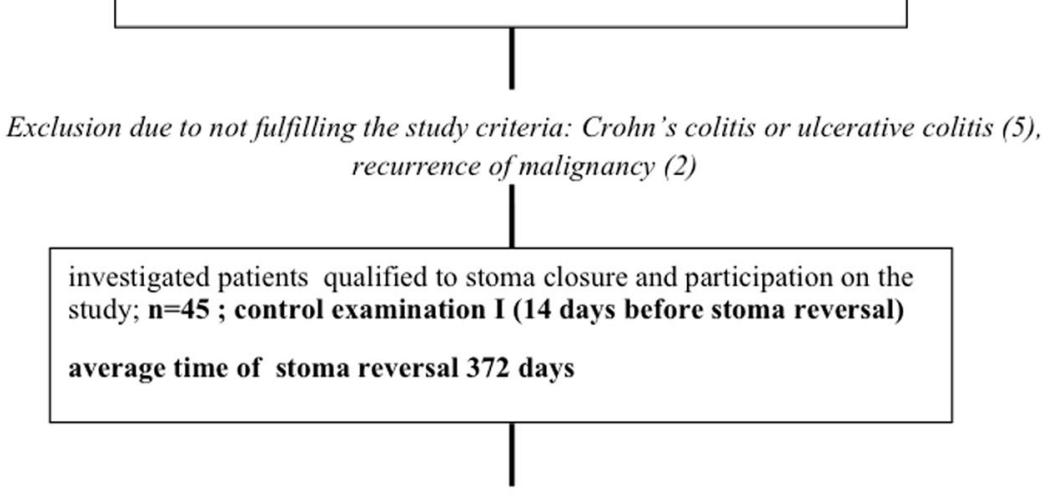

Falling out of the study: loss of contact with patient (2)

nvestigated patients after stoma reversal; $\mathbf{n}=\mathbf{4 3}$

control examination II (average 88 days after stoma reversal)

Falling out of the study: loss of contact with patient, no acceptation of the invitation for the investigation, patient's death (20)

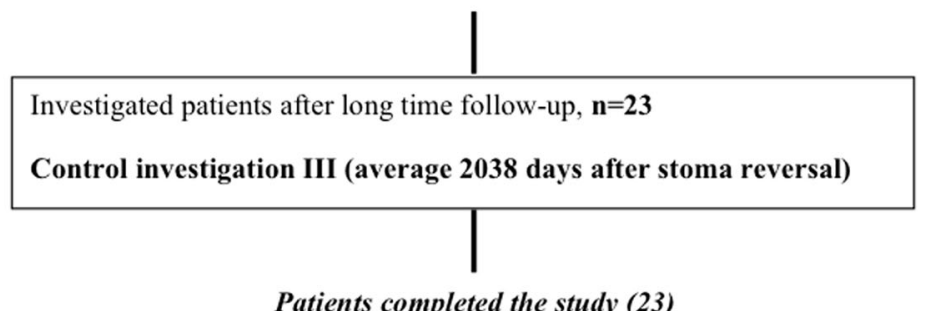

Data of all patients completed the study were calculated as 3 groups: A (investigation I), BI (investigation II) and B2 (investigation III). 
Table 2 The incidence of endoscopic, histological and clinical inflammation of the mucosa in each study group

\begin{tabular}{llll}
\hline Signs of inflammation: & $\begin{array}{l}\text { Investigation A before } \\
\text { reversal }(n=23)\end{array}$ & $\begin{array}{l}\text { Investigation B1 3 months } \\
\text { after reversal }(n=23)\end{array}$ & $\begin{array}{l}\text { Investigation B2 5.6 years } \\
\text { after reversal }(n=23)\end{array}$ \\
\hline Endoscopic inflammation (score $\geq 1)(\%)$ & $\begin{array}{l}22 \text { patients } \\
(95.6)\end{array}$ & $\begin{array}{l}4 \text { patients } \\
(17.4)\end{array}$ & $\begin{array}{l}12 \text { patients } \\
(52.2)\end{array}$ \\
Histologic inflammation (score $\geq 1)(\%)$ & $\begin{array}{l}23 \text { patients } \\
(100)\end{array}$ & $\begin{array}{l}22 \text { patients } \\
(95.6)\end{array}$ & $\begin{array}{l}23 \text { patients } \\
(100)\end{array}$ \\
Clinical symptoms of inflammation (score $\geq 1)(\%)$ & 19 patients & 6 patients & 6 patients \\
& $(82.6)$ & $(26.1)$ & $(26.1)$ \\
Patients without endoscopic $(0$ point) histological $(0$ or 1 point) & 0 pratient & $(0$ patients & 3 patients \\
clinical (0 point) signs of inflammation $(\%)$ & $(0)$ & $(34.8)$ & $(13)$
\end{tabular}

\section{Results}

Signs of DC were observed by endoscopy, histology and clinical score in the study group during the period of faecal diversion. Twenty-two patients showed inflammation on endoscopy, all 23 patients had histopathological inflammation and 19 showed clinical symptoms, valeted as a typical for DC (Table 2).

Three months after stoma closure, a significant decrease in the severity of inflammation was observed for endoscopic, histological and clinical scores (Table 3).

There was no statistically significant change in the Ki67 positivity. At a median 5.6 years after surgery, the incidence and severity of endoscopically detected inflammation increased, but no significant difference was found between the first and second examinations after stoma reversal (B1 and B2). The incidence of histological inflammation was high, as seen in both previous examinations. The severity of inflammation increased and was significantly higher than that at B1. No significant differences were found between the severity of histological inflammation in specimens taken during diversion (A) and at B2. The Ki67 positivity percentage decreased not significantly from that at the previous examination (B1). However, the positive trend was observed.

Changes in inflammation activity assessed by endoscopic, histopathological and clinical scores and Ki67 positivity percentage are shown in Fig. 2.

\section{Discussion}

DC is still a problem and probably will remain so in the future [6]. However, many patients need to maintain a colostomy for long periods, and some will never attain the reconstruction of intestinal continuity. As a consequence, it is expected that DC

Table 3 Severity of endoscopic, histological and clinical inflammation, and Ki67 reactivity before and after stoma reversal with level of significance (Wilcoxon-Mann-Whitney test was used to determine $p$ value) in study and control groups

\begin{tabular}{|c|c|c|c|c|c|}
\hline & A & B1 & B2 & $\mathrm{C}$ & $p$ \\
\hline Inflammation by endoscopic score (Harig) & $\begin{array}{l}\text { Mean } 3.17 \\
\text { SD } 2.14 \\
\text { Median } 3\end{array}$ & $\begin{array}{l}\text { Mean } 0.22 \\
\text { SD } 0.52 \\
\text { Median } 0\end{array}$ & $\begin{array}{l}\text { Mean } 0.65 \\
\text { SD } 0.88 \\
\text { Median } 1\end{array}$ & $\begin{array}{l}\text { Mean } 0.14 \\
\text { SD } 0.36 \\
\text { Median } 0\end{array}$ & $\begin{array}{l}\text { A vs. B1 } 0.0002 \\
\text { A vs. B2 } 0.0006 \\
\text { A vs. C } 0.0000 \\
\text { B1 vs. B2 } 0.2347 \\
\text { B2 vs. C } 0.0001\end{array}$ \\
\hline Inflammation by histological score & $\begin{array}{l}\text { Mean } 3.13 \\
\text { SD } 1.82 \\
\text { median } 3\end{array}$ & $\begin{array}{l}\text { Mean } 1.48 \\
\text { SD } 0.66 \\
\text { Median } 1\end{array}$ & $\begin{array}{l}\text { Mean } 2.44 \\
\text { SD } 1.37 \\
\text { Median } 2\end{array}$ & $\begin{array}{l}\text { Mean } 0.5 \\
\text { SD } 0.52 \\
\text { Median } 0.5\end{array}$ & $\begin{array}{l}\text { A vs. B1 } 0.0024 \\
\text { A vs. B2 } 0.3868 \\
\text { A vs. C } 0.0000 \\
\text { B1 vs. B2 } 0.0165\end{array}$ \\
\hline Clinical symptom score & $\begin{array}{l}\text { Mean } 2 \\
\text { SD } 1.57 \\
\text { Median } 2\end{array}$ & $\begin{array}{l}\text { Mean } 0.52 \\
\text { SD } 1.08 \\
\text { Median } 0\end{array}$ & $\begin{array}{l}\text { Mean } 0.38 \\
\text { SD } 0.78 \\
\text { Median } 0\end{array}$ & $\begin{array}{l}\text { Mean } 0.21 \\
\text { SD } 0.43 \\
\text { Median } 0\end{array}$ & $\begin{array}{l}\text { A vs. B1 } 0.0008 \\
\text { A vs. B2 } 0.0020 \\
\text { A vs. C } 0.0008 \\
\text { B1 vs. B2 } 1.0000 \\
\text { B2 vs. C } 1.0000\end{array}$ \\
\hline $\begin{array}{l}\text { Ki67 } \\
\text { (\% positivity) }\end{array}$ & $\begin{array}{l}\text { Mean } 1.05 \\
\text { SD } 2.24 \\
\text { Median } 0\end{array}$ & $\begin{array}{l}\text { Mean } 4.28 \\
\text { SD } 8.77 \\
\text { Median } 0\end{array}$ & $\begin{array}{l}\text { Mean } 0.69 \\
\text { SD } 1.66 \\
\text { Median } 0\end{array}$ & $\begin{array}{l}\text { Mean } 0.24 \\
\text { SD } 0.41 \\
\text { Median } 0\end{array}$ & $\begin{array}{l}\text { A vs. B1 } 0.2327 \\
\text { A vs. B2 } 1.0000 \\
\text { A vs. C } 0.0025 \\
\text { B1 vs. B2 } 0.0969 \\
\text { B2 vs. C } 0.0000\end{array}$ \\
\hline
\end{tabular}




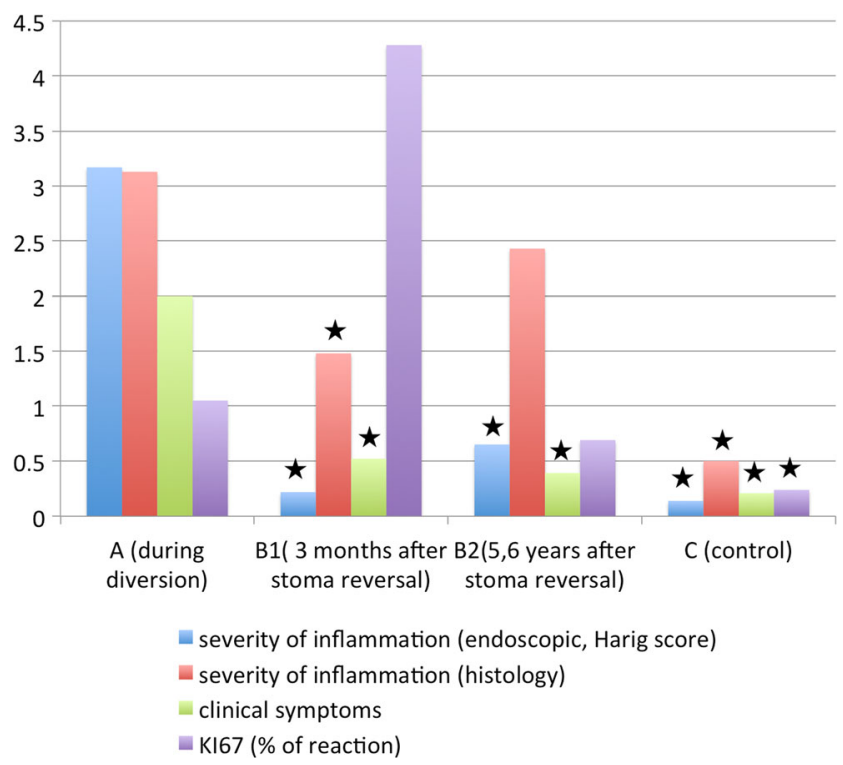

Fig. 2 Changes in inflammation activity assessed by endoscopic, histological and clinical scores, and Ki67 positivity percentage. The statistically significant differences between analysed parameter in group A and other groups are marked with black star (details are in Table 3)

will impair the quality of life of a significant number of patients [7].

DC, especially as identified by endoscopic and histological investigations, is very common in patients with stoma and can occur in up to $100 \%$ of these patients [4], but there is usually no significant correlation between the results of endoscopy and histology and the clinical symptoms. In our study, we found no correlation between the clinical symptoms and the endoscopic and histological severity of DC. Other authors also report no correlation between the endoscopic or histological findings and symptoms such as mucous discharge, bleeding, abdominal pain and tenesmus investigated before and after stoma reversal [3].

There are different methods of treatment for DC, of which the most effective seems to be SCFA, usually by means of butyrate enemas $[8,9]$. Promising results have also been reported for autologous faecal transplantation [10]. Most authors emphasize that although DC can be treated conservatively, the best and most successful method of DC treatment is surgery to reconstruct digestive tract continuity $[9,11]$. Most studies of DC are performed only up to stoma closure or for a short time thereafter, and no serious clinical problems have been reported. There is very limited follow-up information about the period after reconstruction of digestive tract continuity. In one Korean study, the incidence of symptomatic DC was reported as $63.3 \%$ after ileostomy creation, and $46.6 \% 5$ 6 months after ileostomy closure; however, $30 \%$ of patients developed diarrhoea as a new symptom [3]. Interesting data were presented by Pacheco et al. [7]: during experimental studies on the treatment of DC with either glutamine or butyrate, significant reductions in the density of collagen fibres in tissue and in the rate of apoptosis within the epithelium were observed, as well as a decrease in the levels of inflammatory cytokines. These results may suggest that in non-treated DC, both fibrosis and apoptosis may be increased.

Our observation of histological inflammation in patients investigated several years after stoma closure is a surprising result that is difficult to interpret unambiguously. However, the results of the studies presented here suggest the possibility that inflammatory lesions persist, or even in some cases, develop further, as a continuation of the morphological and molecular changes in the colonic mucosa.

A completely opposite trend was observed in the analysis of Ki67 positivity. Ki67 was used as cellular marker for proliferation, also commonly coexisting in premalignant and malignant conditions.

The low level observed during diversion increased shortly after digestive tract restoration, but after several years, the level decreased to one similar to that observed during diversion. These observed changes were not statistically significant, probably because of the high value of the standard deviation and the small numbers of patients investigated. A low level of Ki67 positivity may be correlated with low proliferation. This is supported by the observation that prolonged diversion causes involution and atrophy of the relevant segment. The clinical effect of this situation can be a poor functional outcome [12]. The low level of Ki67 positivity in DC also correlates with a low possibility of malignancy. It is also possible, comparing individuals with ulcerative colitis and those with DC, that the different tissue expression patterns exhibited by mucins may be related to a lower possibility of neoplastic transformation in gut segments that are excluded from the faecal stream because of diseases other than inflammatory intestinal diseases [13]. After stoma closure, Ki67 positivity increased ( 1.05 to $4.28 \%$ reactivity), while in the long-term follow-up, we observed decreasing Ki67 positivity, compared to patients with colostomy before stoma reversal (group A) and shortly after stoma closure (group B1). From the other point, it is necessary to remember that in all patients after stoma formation and reversal (A, B1, B2), positivity of Ki67 was higher than that in control group (C). It can be explained as a result of diversion colitis, stimulating the mucosal cells to proliferation; also, long time after stoma reversal, there is lack of evidences to clearly explain this fact.

The decreased level of Ki67 correlated with greater severity of morphological inflammation. Only a non-significant increase in the endoscopic signs of inflammation and no increase in the severity of clinical symptoms were observed.

The observations presented here demonstrate the long-term consequences of DC. After stoma reversal, all manifestations of colitis decreased significantly, but after several years, inflammation was observed at a morphological level. There are no data in the literature to compare with this observation, and therefore, further long-term study of DC patients is necessary. 
Of course, small number of patients analysed in our paper is a strong limitation of the study, and the presented results and conclusions should be interpreted with caution.

It is difficult to identify the factors potentially influencing the risk of histological inflammation several years after stoma closure. There is controversy regarding histopathological analyses of colon mucosal segments that have been excluded from the faecal stream, which demonstrates that the disease follows a variable course and that there is no characteristic pattern of changes [14-16].

A unique feature of this study is the long observation time, which sheds a slightly different light on the assessment of the natural course of DC and its consequences in the long term after the restoration of GI tract continuity. The histological inflammation of the colonic mucosa observed many years after stoma closure in our study warrants further investigation of this phenomenon.

Open Access This article is distributed under the terms of the Creative Commons Attribution 4.0 International License (http:// creativecommons.org/licenses/by/4.0/), which permits unrestricted use, distribution, and reproduction in any medium, provided you give appropriate credit to the original author(s) and the source, provide a link to the Creative Commons license, and indicate if changes were made.

\section{References}

1. Glotzer DJ, Glick ME, Goldman H (1981) Proctitis and colitis following diversion of the fecal stream. Gastroenterology 80:438441

2. Harig JM, Soergel KH, Komorowski RA, Wood CM (1989 Jan 5) Treatment of diversion colitis with short-chain-fatty acid irrigation. N Engl J Med 320(1):23-28

3. Son DN, Choi DJ, Woo SU, Kim J, Keom BR, Kim CH, Baek SJ, Kim SH (2013) Relationship between diversion colitis and quality of life in rectal cancer. World J Gastroenterol 19(4):542-549

4. Baek SJ, Kim SH, Lee CK, Roh KH, Keum B, Kim CH, Kim J (2014) Relationship between the severity of diversion colitis and the composition of colonic bacteria: a prospective study. Gut Liver $8(2): 170-176$

5. R Core Team (2014). R: a language and environment for statistical computing. R Foundation for Statistical Computing, Vienna, Austria. URL http://www.R-project.org/.

6. Szczepkowski M, Banasiewicz T, Krokowicz P, Dziki A, Wallner G, Drews M, Herman R, Lorenc Z, Richter P, Bielecki K, Tarnowski W, Kruszewski J, Kładny J, Głuszek S, Zegarski W, Kielan W, Paśnik K, Jackowski M, Wyleżoł M, Stojcev Z, Przywózka A (2014) Polish consensus statement on the protective stoma. Pol Przegl Chir 86(8):391-404

7. Pacheco RG, Esposito CC, Müller LC, Castelo-Branco MT, Quintella LP, Chagas VL, de Souza HS, Schanaider A (2012) Use of butyrate or glutamine in enema solution reduces inflammation and fibrosis in experimental diversion colitis. World J Gastroenterol 18(32):4278-4287

8. Tortora F, Purchiaroni E, Scarpellini V, Ojetti M, Gabrielli G, Vitale G, Giovanni A (2012) Gasbarrini: colitides. Eur Rev Med Pharmacol Sci 16(13):1795-1805

9. Szczepkowski M, Kobus A, Borycka K (2008) How to treat diversion colitis?: current state of medical knowledge, own research and experience. Acta Chir Iugosl 55(3):77-81

10. Gundling F, Tiller M, Agha A, Schepp W, Iesalnieks I (2015 Jan) Successful autologous fecal transplantation for chronic diversion colitis. Tech Coloproctol 19(1):51-52

11. Szczepkowski M.: Clinical pathology of diversion colitis. Centre for Postgraduate Medical Education, Warsaw, 2002.

12. Koutroubakis IE (2008) Spectrum of non-inflammatory bowel disease and non-infectious colitis. World J Gastroenterol 14(48):72777279

13. Martinez CAR, Nonose R, Spadari APP, Máximo FR, Priolli DG, Pereira JA, Margarido NF (2010) Quantification by computerized morphometry of tissue levels of sulfomucins and sialomucins in diversion colitis in rats. Acta Cir Bras 25(3):231-240

14. Kiely EM, Ajayi NA, Wheele RA, Malone M (2001) Diversion procto-colitis: response to treatment with short-chain fatty acids. J Pediatr Surg 36:1514-1517

15. Giardiello FM, Lazenby AJ, Bayless TM (1995) The new colitides: collagenous, lymphocytic, and diversion colitis. Gastroenterol Clin N Am 24:717-729

16. Biondo-Simões MLP, Greca FH, Ioshi S, Abicalaffe MD, Colnaghi MC, Mattos e Silva E, Yamasaki ES, Smaniotto G (2000) Colite do cólon excluso: modelo experimental em ratos. Acta Cir Bras 15(Suppl. 3):7-11 